\title{
Accessibility and use of Primary Health Care: how conclusive is the social-economical situation in Antwerp?
}

\author{
H. Philips ${ }^{1}$, P. Rotthier ${ }^{2}$, L. Meyvis ${ }^{3}$, R. Remmen ${ }^{1}$ \\ ${ }^{1}$ Vakgroep Eerstelijns- en Interdisciplinaire Zorg (ELIZA), University of Antwerp, Antwerp, Belgium, ${ }^{2}$ Stad \\ Antwerpen, Studiedienst Stadsobservatie, Belgium, ${ }^{3}$ OCMW Antwerpen, Antwerp, Belgium
}

\begin{abstract}
Background: The percentage of households that delays medical assistance due to financial reasons is slowly increasing. Moreover, some groups of the population do not ever find their way to primary health care and end up unnecessarily in the emergency department or with specialists. This study wants to examine how primary health care can be made accessible to these groups.

Aim: In this study, we aim to discover whether in a city such as Antwerp primary health care is accessible to everyone.

Method: The statistics were collected from the Health Care Survey done by the Welfare Services Antwerp in cooperation with the City of Antwerp. The questions were asked in three different ways: a postal questionnaire, a telephone questionnaire and a face-to-face interview.

Results: We determined that people who live on social welfare delay medical help due to financial reasons more frequently than the global Antwerp population. They often do not have a regular general practitioner (GP). Especially single parents, house-wives and house-husbands, job-seekers, incapacitated people unable to work, unskilled workers and foreigners are among the vulnerable groups where accessibility to primary health care is a concern.

Conclusion: If we hope to improve the accessibility of primary health care, we must first and foremost inform the above-mentioned groups of the insurability and how this is applied. When this is fulfilled, it will be easier for the GP to receive this vulnerable group within the primary care system, so that the help of specialized care, which is often unnecessary, can be reduced.
\end{abstract}

Keywords: Primary care, Accessibility of health services, Socioeconomic factors

\section{Introduction}

Due to socio-economic factors not everyone has equal access to primary health care. ${ }^{1}$ This problem comes up more and more in the international literature and at primary congresses such as WONCA. $^{2-4}$ In spite of the swift evolution in new techniques and improvements in scientific knowledge, care is still limited to that part of the population that finds its own way to the care worker. In the Health Questionnaire by the Scientific Institute of Public Health in 2008 , it appears that $12 \%$ of households in the Flemish region had to delay medical expenditure. That percentage is on the increase; in 2004 it was only $6.2 \%$. In particular, minority and socially deprived groups are in danger of 'missing the boat' while they are the ones that can most benefit from health care. ${ }^{5}$

Correspondence to: Hilde Philips, Universiteit Antwerpen, Campus Drie Eiken, Universiteitsplein 1, Geb R, 3de verd. 2610 Wilrijk, Belgium. Email: hilde.philips@ua.ac.be
Strengthening primary care is considered to be one of the most important solutions to improving accessibility to care. ${ }^{6}$

Certain groups have difficulty accessing care not only during normal office hours, but also outside of office hours and certain minority groups need extra attention. It is often the socially deprived (uninsured, non-native speakers, foreigners) who seek refuge with emergency departments despite normal care being available. ${ }^{7}$ This phenomenon is also mentioned in the international scientific literature. ${ }^{8-10}$ The result is probably not only dependent on the health care system of a certain country (whether or not there is free access to primary, secondary or third-level care, payment per visit or third-party payment) but also on the visibility of the primary care. ${ }^{6}$

To strive for equality within the medical care system two points of interest would appear to be of importance: on the one hand including as many inhabitants as possible in an insurance system, which would notably increase the access to acute care, but 
also strengthening and making primary care accessible, which would seem to have an immediate effect on the quality of care. ${ }^{11}$

\section{Method}

Study set-up and participants

The data was collected from a health survey organized in 2010 by the Welfare Services (OCMW) Antwerp in cooperation with the City of Antwerp. The target group was primarily the population of Antwerp. Because the focus of the questionnaire lay partly on the connection between health and use of health care on the one hand and deprivation on the other a decision was made to increase the random survey to include a sample of citizens who live on welfare. In the total survey, people on welfare are over-represented. We made this choice because the deprived are a difficult group to approach by questionnaires and in addition to include enough citizens in a deprived situation in the survey for allowing valid statistically conclusions.

The questioning was done in three different ways. Most of the Antwerp citizens were approached by mail. This was supplemented with a telephone questionnaire including five hundred citizens. The people on welfare were face-to-face interviewed. The recruitment and questioning of the people on welfare was done in the social centre of the OCMW. Due to the difference in the way people on welfare and the other citizens of Antwerp were questioned, analysis of both groups must be viewed separately. The difference in method of approaching both groups has possibly an important impact on the way correspondents answered.

\section{Methods of analysis}

To further evaluate the access and use of health care, we based ourselves on the following question in the survey: 'Did you postpone medical care in the last twelve months due to financial reasons?'

We performed a logistical regression with the group of Antwerp citizens, whereby the dependent variable may or may not have been a delay of medical care for financial reasons. The independent variables are the personal factors such as age, gender, ethnical background, socioeconomic factors and family circumstances. In addition, we included the presence and impact of illness, psychological problems, sleeplessness and stress. Finally, we inquired whether the knowledge of the systems encouraging access, such as the 'maximum-bill', the Omniostatute and the third-party payment has had an influence on the postponement behaviour. The group on welfare was too small to execute such an analysis. Due to the above-described reasons we did not include this group in the general group of Antwerp citizens.

\section{Results}

\section{Response to the questionnaire}

The questionnaire was answered by 2662 citizens of Antwerp. It included 2126 respondents who were approached by mail and 536 who were phoned. Initially 7000 questionnaires were sent out. Thus we achieved a response degree of $30 \%$. The telephone response was also $30 \%$.

We interviewed additionally 276 people on welfare benefits in face-to-face meetings. These interviews were organized at the social centre of the OCMW and can be considered an exit-poll of the OCMW clients. We aimed at 400 respondents but did not achieve this due to the difficult accessibility of the target group.

\section{Use of primary care}

In the survey we estimated as to how many people have a regular GP. Only 7\% of Antwerp citizens responded that they did not have a regular GP. However, with people on benefits the percentage was $20 \%$.

In the Health Care Survey the question was also asked if in the 12 months before the survey medical care was delayed because of financial reasons and $13.6 \%$ of the Antwerp citizens admitted to delaying care for that reason. With people on welfare the percentage rose to $39.1 \%$ (Table 1). On further enquiry into the type of care citizens of Antwerp deferred, first came the dentist (48\%) then a visit to a specialist $(34 \%)$ or to the GP (34\%). With people on welfare who deferred care it involved mainly going to the GP $(50 \%)$. Also a visit to the dentist $(32 \%)$ or the specialist $(25 \%)$ or purchase of medication $(30 \%)$ was often delayed.

\section{Delay due to financial reasons}

In the final regression model we retained age, ethnic background, family circumstances, socio-economic situation, level of education, and the presence of psychological problems, stress and sleeplessness and lastly the knowledge of the third-party payment as explainable variable for delaying care for financial reasons (Table 2). The model has a R2 Nagelkerke of 0.268 which means that the model explains $27 \%$ of the variation in financial accessibility to medical care.

As far as the demographic background is concerned, foreigners delayed care because of financial reasons more than natives. Single parents also delayed care more. Children still living at home with parents/grandparents showed less delay. Where age was concerned it showed that people of 40-50 years of age delayed care significantly less compared to younger people.

According to the socio-economical background job-seekers were more inclined to delay medical care.

\section{Table 1 Summary of accessibility to medical care}

\begin{tabular}{lcl}
\hline Category & $\begin{array}{l}\text { \% that has } \\
\text { no regular GP }\end{array}$ & $\begin{array}{l}\text { \% that has delayed } \\
\text { medical care }\end{array}$ \\
\hline General sample & 5.4 & 13.6 \\
People on benefits & 19.9 & 39.1 \\
\hline
\end{tabular}


Self-employed did this least. The level of education also plays a role: people without a degree or with a special education degree, delayed care (Table 2).

The presence of psychological problems, sleeplessness and stress are linked to delayed behaviour.

Finally, it appears that individuals knowing the third-party payment system delay care more than individuals not knowing this payment system. Knowledge of the Omnio-statute or of the maximum-bill had apparently no impact.

\section{Discussion \\ Extra attention for people on welfare}

This study includes data of 2662 respondents, which, with a response rate of $30 \%$ is a quite a good representative sample. The researchers decided upon an extra and methodically different approach to questioning people on welfare because according to the literature they belong to the population at risk for delaying medical help. This extra questioning is certainly of added value.

Considering that the questioning of the 276 people on welfare was methodologically different and it would not be correct to add this information to the databank, in this way weakening the statistical analysis. Because of this we only give a descriptive analysis of the results obtained in these participants.

In the general sample of the study we note that $13.6 \%$ have deferred medical help in the last 12 months because of financial reasons. In the Medical Health Survey of 2008, 12\% was noted for the whole of the Flemish region. This percentage is thus increasing and the Antwerp result is thus relatively comparable to the Flemish one. However comparing the people on welfare we determine that $39.1 \%$ have delayed medical help. We also note that this group is the highest percentage without a regular GP. For this category attaining health insurance as well as easier accessibility to primary health care is a priority. A possible indicator hereby is the percentage with a regular GP. ${ }^{11}$

\section{Stress and psychological problems}

In the global sample, we note that extra attention is mostly needed for single parents, house-wives and

Table 2 Logistical regression model. The independent variable is the delaying of help as compared to not delaying help due to financial reasons (the first category is the reference category)

\begin{tabular}{|c|c|c|c|c|}
\hline \multirow[b]{2}{*}{ Independent variable } & & \multicolumn{2}{|c|}{ Parameters } & \multirow[b]{2}{*}{$95 \% \mathrm{Cl}$ for OR } \\
\hline & & OR & Sign. & \\
\hline \multirow[t]{3}{*}{ Origin } & Native (ref) & & 0.000 & \\
\hline & EU & 1.664 & 0.028 & $1.057-2.620$ \\
\hline & Non EU & 2.116 & 0.000 & $1.463-3.061$ \\
\hline \multirow[t]{6}{*}{ Family circumstances } & Single (ref) & & 0.002 & \\
\hline & With partner without children & 0.755 & 0.185 & $0.497-1.145$ \\
\hline & With partner and children & 0.744 & 0.180 & $0.483-1.146$ \\
\hline & Single parent & 1.870 & 0.038 & $1.035-3.377$ \\
\hline & Living with parents/grandparents & 0.345 & 0.004 & $0.167-0.713$ \\
\hline & Other type & 0.427 & 0.196 & $0.117-1.551$ \\
\hline \multirow[t]{11}{*}{ Socio-economical position } & Labourer (ref) & & 0.000 & \\
\hline & Office worker & 0.611 & 0.060 & $0.366-1.020$ \\
\hline & Management & 0.419 & 0.183 & $0.116-1.507$ \\
\hline & Self-employed & 0.176 & 0.008 & $0.049-0.634$ \\
\hline & Public servant & 0.412 & 0.059 & $0.164-1.035$ \\
\hline & (Early) retired & 0.630 & 0.351 & $0.238-1.665$ \\
\hline & Job-seeker & 2.488 & 0.001 & $1.441-4.297$ \\
\hline & House-wife/house-husband & 1.427 & 0.260 & $0.769-2.650$ \\
\hline & Student & 0.630 & 0.247 & $0.288-1.378$ \\
\hline & Incapacitated unable to work & 1.812 & 0.069 & $0.954-3.442$ \\
\hline & Other & 0.724 & 0.565 & $0.240-2.179$ \\
\hline \multirow[t]{6}{*}{ Degree } & Higher education (ref) & & 0.000 & \\
\hline & Unskilled & 3.743 & 0.000 & $2.006-6.985$ \\
\hline & Primary education & 1.409 & 0.248 & $0.788-2.522$ \\
\hline & Secondary education & 1.996 & 0.004 & $1.244-3.202$ \\
\hline & Higher secondary education & 1.384 & 0.105 & $0.935-2.050$ \\
\hline & Special needs education & 3.167 & 0.006 & $1.388-7.228$ \\
\hline \multirow[t]{7}{*}{ Age } & $16-24$ (ref) & & 0.011 & \\
\hline & $25-34$ & 0.824 & 0.570 & $0.423-1.606$ \\
\hline & $35-44$ & 0.702 & 0.325 & $0.346-1.422$ \\
\hline & $45-54$ & 0.428 & 0.023 & $0.206-0.890$ \\
\hline & $55-64$ & 0.294 & 0.003 & $0.129-0.667$ \\
\hline & $65-74$ & 0.406 & 0.151 & $0.119-1.390$ \\
\hline & $75-99$ & 0.473 & 0.233 & $0.138-1.621$ \\
\hline \multicolumn{2}{|c|}{ Knowledge of third-party payment system (ref=yes) } & 0.656 & 0.009 & $0.479-0.898$ \\
\hline \multicolumn{2}{|c|}{ Psychological problem (ref=no psychological problem) } & 1.896 & 0.001 & $1.286-2.795$ \\
\hline \multicolumn{2}{|c|}{ Sleeplessness (ref=no sleeplessness) } & 1.824 & 0.001 & $1.293-2.573$ \\
\hline \multicolumn{2}{|l|}{ Stress (ref=no stress) } & 2.037 & 0.000 & $1.465-2.834$ \\
\hline \multicolumn{2}{|l|}{ Constant } & 0.150 & 0.000 & \\
\hline
\end{tabular}


house-husbands, job-seekers, incapacitated people unable to work, unskilled workers and foreigners.

It is notable that the presence of psychological problems, sleeplessness and stress are related to deferment behaviour. In persons with one of these problems the chance of delaying looking for medical help is greater. It is difficult to explain this relation. The question here is whether there is a direct causal association and if so, which direction it takes. On the one hand it could mean that one should seek medical care for these problems but because there is no physical problem, medical care is delayed. On the other hand, it could well be that just because of financial problems and/or limited access to medical care; people have stress and psychological problems. It is also highly likely that these symptoms are more prevalent in people with poorer health.

\section{Knowledge of third-party payment}

Finally and surprisingly, it appears that those individuals who know the existence of a third-party payment, delay care more than those who are unaware of it. In the first instance this does not seem logical and one would expect that those with knowledge of the system would not be inclined to delay care. In this case it could however be an indication of how precarious the financial situation is in which they live. It could also be that such a person learns about the system after a moment of care postponement.

\section{Conclusion}

Generally speaking, we can assume that single parents, job-seekers, unskilled workers and foreigners have a greater chance of delaying care behaviour due to financial reasons. These groups are in a more vulnerable situation than others. Although we have not taken income-data into account, we note that vulnerable groups delay care more than other groups. This is strengthened by our findings that the people on welfare show a higher care delaying behaviour than the general Antwerp population.

The government's attention should go to informing this vulnerable population about the health care organization with emphasis on the accessibility of primary care.

Also steps must be taken to ensure that these people can be insured and can achieve the knowledge how to obtain of how it is applied, such as the thirdparty payment system. Once this is done, it will be easier for the GP to attend to this group within primary care. This will decrease the often unnecessary use of specialist help.

\section{Appendix: Case - out on house call with the welfare One euro for a visit to the GP!}

Today I am on a house call to a woman from Guinea. She lives in the hip Park Spoor Noord area in Antwerp. I look for the address and find the front door around the corner; the door is open, no lock, no doorbell... I ring her on her mobile and she directs me to the first floor. I enter a dark area. Everything is neat and tidy, but the flat is small, more a bed-sit and not well appointed. There is a lot of noise from the surrounding flats.

The occupant is pregnant and has a toddler running around the living area, a huge television and since recently...medical insurance.

I ask how she is (she's 'bien') and introduce myself: 'My name is Liesbet, I work for the Welfare. I rang you recently to ask if it was alright if we could talk about your health together.'

Kesso, that is her name, indicates that she speaks little Dutch. We switch to a Dutch-French conversation. Kesso is a bit reserved but we slowly make headway. She tells me that the father of her child is with another woman and only visits sporadically. We talk about her child and her pregnancy. I ask with regard to the pregnancy if she has a GP. She tells me that she goes to a doctor in the area; she is very happy with this doctor because the doctor helps her out. I ask how much she has to pay this doctor and she tells me, nothing at first but now $22 €$ per visit. She does not understand this. I ask if she has medical insurance. She looks at me wide-eyed and with a frown. I use several synonyms: medical insurance, mutuality, CM, Medicare...I try SIS-card...! Yes! She has one. She shows me the card and I ask to see stickers, vignette, and logos. In answer she shows me the medical insurance book, with Medicare stickers.

I take my photo album out of my backpack and tell my story.

I tell her, using photos and short sentences about health care in Belgium:

- that almost everyone in Belgium has a GP;

- that a sore throat is not urgent enough to go to the emergency department;

- that a GMD application has many advantages;

- that you can ask to pay with a sticker at the GPs;

- that you can go to the 'doctor on call' at the weekend;

- that there are several benefits if you have an Omniostatute;

- that it is better that you go the doctor yourself rather than that the doctor comes to you;

- that it is better if you can speak for yourself rather than let your children translate;

- ...

During the conversation other stories come to the surface. For example Kesso is enthusiastic about 'paying with a sticker'. She tells me that it is not always easy to have money left over to go to the doctor, that she prefers to wait and see if it gets better or until the start of the new month. Sometimes it is difficult, if her daughter is ill, she goes to the hospital. Then she does not have to pay. But now she is happy to know that she can go to the doctor, for one euro. 
Now the questions come thick and fast: about being 'alone', godparents for her child, having no friends and no hobbies, only her TV, but there is little time left and we arrange our next house call. She asks me to call her because she has no credit on her mobile. After a prolonged and hearty 'merci' I am back on the pavement. I find my way back and continue on to my next client.

L. Meyvis, Welfare Service (OCMW) Antwerp, health department

\section{Kesso's financial situation}

Single parent with one daughter.

\section{INCOME}

Welfare support: 1026.91 euro

Increased child allowance: 128.38 euro

$=1115.29$ euro per month

\section{FIXED PAYMENTS*}

Rent of flat: 470 euro per month

Gas, electricity: 100 euro per month

TV/Internet (basic): 45 euro per month

Mobile (basic): 25 euro per month

Fire and liability insurance: 12 euro per month

Health insurance: 6.7 euro per month

Hospital insurance: 0.83 euro per month

Public transport: 2.5 euro per month

$=682.03$ euro per month

PRIMARY NEEDS (food \& drink only)*

$=375$ euro per month

\section{OTHER}

98.26 euro per month

To be paid: debt repayment rent deposit 25 euro per month, doctors bills, washing detergent, chemist, child care, hairdresser, entertainment... *figures based on data from the debt mediatory service (minimum)

The photo book 'Health Care in Belgium' can be seen or downloaded via www.ocmw.antwerpen.be

More information can be obtained via: gezondheid @ocmw.antwerpen.be

\section{References}

1 Avalosse H, Gillis O, Cornelis K, Mertens R. Gezondheidsongelijkheid: Sociale ongelijkheden op het vlak van gezondheid: vaststellingen op basis van de gegevens van de ziekenfondsen. CM Informatie. 2008;233:3-15.

2 van Royen P, Beyer M, Chevallier P, Eilat-Tsanani S, Lionis C, Peremans L, et al. Series: The research agenda for general practice/family medicine and primary health care in Europe. Part 5: Needs and implications for future research and policy. Eur J Gen Pract. 2010;16(4): 244-8.

3 De Maeseneer J, Willems S. Commentary on Series: The research agenda for general practice/family medicine and primary health care in Europe. Part 5: Needs and implications for future research and policy. Eur J Gen Pract. 2010;16(4): 203-4.

4 Baum FE, Bégin M, Houweling TA, Taylor S. Changes not for the fainthearted: reorienting health care systems toward health equity through action on the social determinants of health. Am J Public Health. 2009;99(11):1967-74.

5 Keppel K, Bilheimer L, Gurley L. Improving population health and reducing health care disparities. Health Affairs. 2007;26(5):1281-92.

6 Kantayya VS, Lidvall SJ. Community health centers: disparities in health care in the United States 2010. Disease-A-Month. 2010;56(12):681-97.

7 Philips H, Remmen R, De Paepe P, Buylaert W, Van Royen P. Out of hours care: a profile analysis of patients attending the emergency department and the general practitioner on call. BMC Fam Pract. 2010;11:88.

8 Green J, Dale J. Primary care in accident and emergency and general practice: a comparison. Soc Sci Med. 1992;35(8):987-

9 Padela AI, Punekar IR. Emergency medical practice: advancing cultural competence and reducing health care disparities. Acad Emerg Med. 2009;16(1):69-75.

10 Brim C. A descriptive analysis of the non-urgent use of emergency departments. Nurse Res. 2008;15(3):72-88.

11 Starfield B. Commentary: How does 'insurance' improve equity in health? Int J Epidemiol. 2009;38(6):1551-3. 